\title{
Newly diagnosed diabetes: a study of parental satisfaction
}

\author{
D N Lessing, P G F Swift, M A Metcalfe, J D Baum
}

\begin{abstract}
A national survey of 509 parents of children with newly diagnosed diabetes elicited a $92 \%$ response rate, showing that $96 \%$ of children were admitted to hospital, $42 \%$ staying in hospital longer than one week and $41 \%$ received an intravenous infusion. More than $90 \%$ of parents expressed satisfaction with the information given at diagnosis, the preparation they received before discharge home, and the outpatient follow up services. Home visits from a diabetes nurse specialist (DNS) were received by $73 \%$ of families and $44 \%$ reported that the DNS was the most supportive person in the first year after diagnosis. Readmission during the first 12 months after diagnosis was required by $23 \%$ of children, more often in the youngest age group. Poor liaison with schools and the lack of diabetes knowledge in teachers were the sources of greatest dissatisfaction.

Children under the care of paediatricians with no specialist interest in diabetes were significantly more likely to be kept in hospital longer at diagnosis and parents were less satisfied with outpatient care and school liaison. The study supports previous recommendations that diabetes nurse specialists are a priority resource in providing support services and that every district should have a paediatrician with a special interest in diabetes and a designated children's diabetic clinic.
\end{abstract}

(Arch Dis Child 1992;67:1011-1013)

Diabetes in children requires readjustments in family life ${ }^{1}$ with parents expressing a need for support and advice. ${ }^{2}$ There has been little research evaluating parental satisfaction in the support received by children with diabetes. Challen et al asked parents about the support they had received since their child's diagnosis of diabetes mellitus. ${ }^{3}$ Comments made by parents were wide ranging and led them to suggest ways in which family support might be improved.

In 1988 a national survey of the incidence of childhood diabetes was undertaken using the active reporting system of the British Paediatric Surveillance Unit. ${ }^{4}$ In the same year a working party of the British Paediatric Association (BPA) investigated the services provided for children with diabetes in the UK. ${ }^{5}$ The data available from these two surveys formed the basis of this assessment of parental satisfaction with hospital and community services during the 12 months after the diagnosis of diabetes. We were particularly interested in whether there was any association between the level of parental satisfaction and paediatricians' specialist interest.
Subjects and methods

The study sample was selected from the 1988 national survey of 1174 families who returned the original questionnaire. Information was available on the parental social class and education, the age of the child at diagnosis, and the specialist interest of the child's paediatrician. The latter was assessed by the answers given to three key questions: the paediatrician's stated level of interest in diabetes, clinic size, and clinic type. The working party then assigned paediatricians to one of four groups as follows:

(A) Paediatricians fulfilling the following three criteria: (1) specialist diabetologist/ endocrinologist or with a major interest in diabetes; (2) caring for more than 40 children with diabetes; (3) seeing children in a designated paediatric diabetic clinic.

(B) Paediatricians fulfilling any two of the above criteria.

(C) Paediatricians fulfilling any one of the above criteria.

(D) Paediatricians not fulfilling any of the above criteria. $^{5}$

The last 509 parents to respond to the initial questionnaire were selected and sent a postal questionnaire. This questionnaire comprised 30 'closed' type questions covering aspects of care at diagnosis, in the outpatients' clinic, at school, and at home. Satisfaction questions were in a four point forced choice format ranging from very satisfied to very dissatisfied. The data was analysed using the Statistical Package for Social Sciences to provide tables and $\chi^{2}$ calculations using as the variables the child's age, specialist grouping of the paediatrician, and mother's level of education (divided into three groups: none, trade or ' $O$ ' levels, 'A' levels, or degree). Assumptions have been made that the mother was the main carer of the child. Only the significant findings are reported.

\section{Results}

Questionnaires were returned by 469 (92\%) parents. There were $114(24 \%)$ children who were under 5 years at diagnosis, $183(39 \%)$ aged 5 to 10 , and $172(37 \%)$ between 11 and 15 .

The percentage of children under the care of paediatricians in groups $\mathrm{A}, \mathrm{B}, \mathrm{C}$, and $\mathrm{D}$ were $30 \%, 21 \%, 21 \%$, and $16 \%$ respectively $(12 \%$ not known) and evenly distributed with regards to the child's age and the mother's education.

\section{DIAGNOSIS AND MANAGEMENT}

A family member was the first to suspect diabetes in $282(60 \%)$ cases and the general practitioner in $128(27 \%)$. There were 452 
(96\%) children admitted to hospital, 261 (58\%) for up to one week, 163 (36\%) for one to two weeks, and $27(6 \%)$ for over two weeks, $41 \%$ receiving an intravenous infusion. Children under the care of paediatricians in group $\mathrm{D}$ were more likely to be kept in hospital longer than one week $\left(\chi^{2}=18.23, \mathrm{df}=6, p=0.006\right)$ irrespective of the child's age or the mother's education.

Readmission during the first year was required by $110(23 \%)$ children, the majority $(81 \%)$ only once or twice. Readmission was significantly more likely to occur in the under 5 age group $\left(\chi^{2}=9 \cdot 64, \mathrm{df}=2, \mathrm{p}=0 \cdot 008\right)$.

\section{PARENTAL INFORMATION AND SATISFACTION} There were 434 (93\%) parents who thought that the information given at initial diagnosis was good or very good, $27(6 \%)$ felt it was poor or very poor, two found it non-existent.

The consultant paediatrician and/or the diabetes nurse specialist (DNS) were reported by $337(72 \%)$ as giving the most useful information on the initial admission. A total of 424 $(90 \%)$ parents felt very well or quite well prepared to cope with their child on discharge and $425(91 \%)$ were satisfied or very satisfied with the help and information they received in the hospital. The parents of children under 5 years were more likely to feel dissatisfied or very dissatisfied $\left(\chi^{2}=9 \cdot 22, \mathrm{df}=2, \mathrm{p}=0 \cdot 01\right)$.

\section{FOLLOW UP}

After discharge from hospital two thirds of the children were seen five or more times in the outpatient clinic with almost one third having seven or more visits in the first year. There were 442 (94\%) parents who saw the consultant paediatrician in outpatients, but only $345(74 \%)$ saw a DNS and $348(74 \%)$ a dietitian. Only 39 (8\%) parents had the option of seeing a social worker at the clinic. Few clinics offered professional psychological support for the family.

There were $422(90 \%)$ parents satisfied or very satisfied with the care and support received in the outpatient clinic. However, 42 (9\%) parents were dissatisfied or very dissatisfied and were more likely to be attending the clinics of paediatricians in group $\mathrm{D}\left(\chi^{2}=23.93, \mathrm{df}=3\right.$, $\mathbf{p}<0.001)$ where the child was less likely to see the DNS $\left(\chi^{2}=18 \cdot 87, \mathrm{df}=3, \mathrm{p}=0.0003\right)$ or the dietitian $\left(\chi^{2}=30 \cdot 13, \mathrm{df}=3, \mathrm{p}<0.001\right)$.

\section{SCHOOLING}

Once back at school one third of children had more time off in the year after diagnosis than in the previous year. Of 374 parents $184(49 \%)$ said that a DNS had visited the school; however, $50 \%$ of parents were concerned about the lack of knowledge and understanding of diabetes by the teachers. Only $48(13 \%)$ children had many: problems with their diabetes at school, the remainder having few or no problems. There were $197(64 \%)$ of 309 parents satisfied or very satisfied with school arrangements while $113(37 \%)$ felt dissatisfied or very dissatisfied. Parents were more likely to feel dissatisfied if under the care of paediatricians in group D compared with those in group $\mathrm{A}\left(\chi^{2}=11.96\right.$, $\mathrm{df}=3, \mathrm{p}=0.008$ ).

\section{HOME MANAGEMENT}

Of $344(73 \%)$ families who received home visits from the DNS, only $141(41 \%)$ said it was on a regular basis.

There were 358 (76\%) families who had few or no problems managing their child's diabetes at home, while $101(22 \%)$ had several or many problems; $449(96 \%)$ parents felt confident in looking after their child in the first year, and $346(74 \%)$ families were very satisfied or satisfied with the care and support received at home. Mothers with children under 5 years of age were significantly less likely to be satisfied $\left(\chi^{2}=8 \cdot 71\right.$, $\mathrm{df}=2, \mathrm{p}=0.01$ ); this was true also of mothers with the middle level of education (in trade or with ' $O$ ' levels $)\left(\chi^{2}=10.9, \mathrm{df}=2, \mathrm{p}=0.004\right)$.

Some 207 (44\%) parents thought the DNS was the most supportive person during the first year; $386(82 \%)$ parents had joined the British Diabetic Association (BDA) and 287 (61\%) said that a local support group also existed, although not all attended.

\section{Discussion}

Studies of consumer satisfaction with medical care have become an important component of health service research. Consumers are becoming more demanding about the type of care they receive and providers are becoming more attentive to their concerns. Not only is patient satisfaction an integral part of quality of care, but patients who are more satisfied and thus more concerned in their own care will be more likely to comply with treatment regimens and may have better outcomes. ${ }^{6}$ Challen et al found the most frequent factor related to satisfaction with services was immediacy of access of professional advice. ${ }^{3}$ Although our study did not specifically ask about immediate availability of professional help, the parents' high level of satisfaction and confidence suggests that this issue had been well covered by the services. Indeed the most striking finding of this study is the high degree of satisfaction parents had with the information and support they received both as inpatients and outpatients. The satisfaction levels are higher than the $80 \%$ quoted in previous studies. ${ }^{7}$ However, parents of the younger children were more likely to be dissatisfied and these children were more likely to be readmitted in the first year. This may reflect both the diffculties in this age group and lack of adequate community resources.

As $90 \%$ of parents were satisfied with outpatient care presumably they viewed these frequent sessions as educational and supportive. Although $94 \%$ of children saw the consultant paediatrician, $26 \%$ had no chance of seeing a dietitian or a specialist nurse as recommended recently by the BDA. ${ }^{8}$ The recommendation by the BPA working party that clinics for diabetic children should be established in each district ${ }^{5}$ was supported by the finding that families attending paediatricians in group $\mathrm{D}$ were significantly less likely to be satisfied. 
The BDA recommends that 'the specialist nurse and/or dietitian should offer to make appropriate contact with the child's school'. This was followed in only $49 \%$ of our study population. Over $50 \%$ of parents expressed lack of confidence in the teaching staff and commented on the teachers' lack of knowledge about diabetes. A recent article argues the need for increasing teachers' awareness of chronic medical conditions. 9

In 1983 Bradbury and Smith assessed the knowledge of teachers who had children with diabetes in their schools. ${ }^{10}$ Only $25 \%$ had an adequate understanding of diabetes and most of the information came from either the pupil with diabetes or their parents and not from medical or nursing personnel. Most schools have a nurse and doctor and they should, with support from the DNS, take a positive advisory role. The lack of confidence in schools expressed by $36 \%$ of parents, is identical to that reported by Challen et al. ${ }^{3}$

Satisfaction for support received at home was midway between that of hospital and school. Parents of younger children were the most dissatisfied. Stein and Jessop, studying a group of children with chronic diseases, found a significant beneficial effect of a 'paediatric home care program' on parental satisfaction. ${ }^{11}$ Paradoxically Moyer found that 82 parents with access to a DNS needed information on more topics and their level of concern was greater compared with 72 parents who had no access to this service. ${ }^{2}$ Watson's study of 78 children with diabetes found that the parents' confidence in caring for their child at home was related to the amount of teaching and discussion they had received in hospital. Parents described the early weeks at home as difficult, associated with feelings of isolation. They would have welcomed supportive visits. ${ }^{12}$ Many districts have now established paediatric home care units which offer a flexible service designed to meet the needs of children and families. ${ }^{13}$ Currently in the UK there are 46 schemes together with 30 specialist schemes. ${ }^{14}$

The BPA working party found that $19 \%$ of UK districts had no DNS service, and in those districts with DNSs only $50 \%$ provided their phone numbers. As the parents of the youngest and most vulnerable children appear to be least satisfied with services, it would seem prudent to target this group in support schemes by providing a DNS service in all districts.

This study has shown that children under the care of paediatricians in group $\mathrm{D}$ (who have less specialist interest in diabetes) were more likely to spend longer in hospital; their families expressed more dissatisfaction with follow up arrangements and were more likely to attend clinics where no DNS or dietitian was available, and they were less happy with school liaison. These findings support the recommendations made in the BPA working party document that children with diabetes should have access to a paediatric diabetes team working within designated children's diabetic clinics. ${ }^{5}$ Such services enhance parental satisfaction which is likely to have beneficial effects on motivation and on outcome.

We would like to thank Novo Nordisk for funding this project and the British Paediatric Surveillance Unit (funded by a grant from The Children Nationwide Medical Research Fund).

1 Thomas D. Living with a diabetic child. In: Baum JD, Kinmonth A-L, eds. Care of the child with diabetes. Edinburgh: Churchill Livingstone, 1985:3-11.

2 Moyer A. Caring for a child with diabetes: the effect of specialist nurse care on parents' needs and concerns. $\mathcal{F} A d v$ Nurs 1989;14:536-45.

3 Challen AH, Davies AG, Williams RJW, Baum JD. Support for families with diabetic children: parents' views. Practical Diabetes 1990;7:26-31.

4 Metcalfe MA, Baum JD. Incidence of insulin dependent diabetes in children under 15 years in the British Isles diabetes in children under 15 years
during 1988. BMF 1991;302:443-7.

5 British Paediatric Association Working Party. The organisation of services for children with diabetes in the United Kingdom: report of the British paediatric working party. Diabetic Med 1990;7:457-64.

6 Svarstad BL, Greenfield S, Kaplan S, et al. Expanding patient involvement with care: effects on patient outcomes. Ann Intern Med 1985;107:520-8.

7 Locker D, Dunt D. Theoretical and methodological issues in sociological studies of consumer satisfaction with medical care. Soc Sci Med 1978;12:283-92.

8 British Diabetic Association Committee. What professional supervision should children with diabetes and their families expect? London: British Diabetic Association, 1989.

9 Brown K, Chadwick J, North J. Using Baker days for teacher education about diabetes. Diabetes update. London: British Diabetic Association, Spring 1990.

10 Bradbury AJ, Smith CS. An assessment of the diabetic knowledge of school teachers. Arch Dis Child 1983;58: knowledge.

11 Stein REK, Jessop DJ. Does paediatric home care make a difference for children with chronic illness? Findings from the Ambulatory Care Treatment Study. Pediatrics 1984;73: 845-53.

12 Watson $\dot{A}$. A study of family attitudes to children with diabetes. Community Med 1972;19 May:122-5.

13 Mair EJ. Paediatric home care: a flexible approach to the family centred care of children with diabetes mellitus. Practical Diabetes 1989;6:173-6.

14 Royal College of Nursing. Directory of paediatric community nursing services. London: Royal College of Nursing, 1991. 